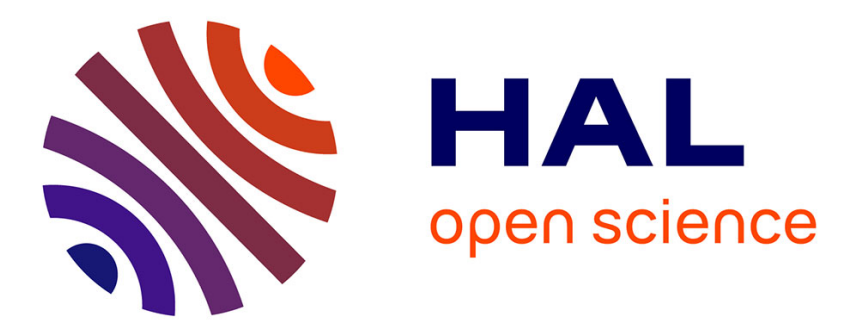

\title{
Localization due to damage in fiber-reinforced composites
}

\author{
François Hild, Per-Lennart Larsson, Frederick A. Leckie
}

\section{To cite this version:}

François Hild, Per-Lennart Larsson, Frederick A. Leckie. Localization due to damage in fiberreinforced composites. International Journal of Solids and Structures, 1992, 29 (24), pp.3221-3238. 10.1016/0020-7683(92)90037-T . hal-01635994

\section{HAL Id: hal-01635994 https://hal.science/hal-01635994}

Submitted on 31 Oct 2019

HAL is a multi-disciplinary open access archive for the deposit and dissemination of scientific research documents, whether they are published or not. The documents may come from teaching and research institutions in France or abroad, or from public or private research centers.
L'archive ouverte pluridisciplinaire HAL, est destinée au dépôt et à la diffusion de documents scientifiques de niveau recherche, publiés ou non, émanant des établissements d'enseignement et de recherche français ou étrangers, des laboratoires publics ou privés. 


\title{
LOCALIZATION DUE TO DAMAGE IN FIBER-REINFORCED COMPOSITES
}

\author{
François Hild $\dagger$. Per-Lennart Larssonị and Frederick A. Leckie \\ Deparment of Mechanical and Environmental Engineering, University of California, \\ Santa Barbara, CA 93106. U.S.A.
}

\begin{abstract}
Ahstract-Fiber pull-out is one of the fracture features of fiber-reinforced ceramic matrix composites. The onset of this mechanism is predicted by using Continuum Damage Mechanics. and corresponds to a localization of the deformations. After deriving two damage models from a uniaxial bundle approach. different configurations are analysed through analytical and numerical (F.E. calculations) methods. For one model some very simple criteria can be derived. whereas for the second one none of these criteria can be derived and the general criterion of localization has to be used.
\end{abstract}

\section{INTRODUCTION}

The aim of this paper is to study the failure of fiber-reinforced ceramic-matrix composites. One of the features of their behavior is fiber pull-out due to fiber breaking. The occurrence of this mechanism is assumed to be described by the appearance of a macro-crack and will be described by a localization of the deformations. The initiation of macro-cracks in a structure during service often constitutes the early stage of the final failure of the structure. Starting from a material that is assumed to be free from any initial defect, the initiation of macro-cracks can be predicted using Continuum Damage Mechanics. This approach has successfully been used for ductile materials (Billardon and Doghri. 1989a.b; Doghri. 1989). The initiation stage is considered as the onset of a surface across which the velocity gradient is discontinuous. Under small deformations assumption, this phenomenon is mainly driven by the dama ge mechanism that causes strain-softening. For ceramic-matrix composites, the damage mechanism is related to fiber breaking.

Stationary waves were studied by Hadamard (1903) in elasticity, by Hill (1962) and Mandel (1962) in elasto-plasticity. Rice (1976) related the locaiization of plastic shear bands to jumps of the velocity gradient. Recently, Borré and Maier (1989) have given necessary and sufficient conditions for the onset of modes inside the body. which extended the results given by Rice (1976), Rice and Rudnicki (1980) and Rudnicki and Rice (1975).

This type of approach will also be used in the study of fiber-reinforced composites. Although localization can be studied at the scale of fibers bonded to a matrix through an interface (Benallal et al. 1991), i.e. at a micro-level. localization can also be anaiysed at a meso-level, where the material is assumed to be homogeneous. Continuum Damage Mechanics, which represents a local approach to fracture. constitutes an efficient tool for this purpose. The progressive deterioration of the material is modeled by an internal variable defined at the meso-level. This variable is called damage. The damage state and the evolution of this variable is obtained through a uniaxial study based on fiber breaking (Coleman. 1958). A 2-D plane stress analysis is performed based on an extended model. The loss of uniqueness and the localization are studied for shear free states. A criterion referring to a critical value of the damage can describe the localization, which constitutes an objective criterion. from a design point of view.

This approach is also used to study a spinning disc made of a fiber-reinforced ceramicmatrix composite. The same criteria are implemented and studied through Finite Element

+Also at Laboratoire de Mécanique et Technologie, E.N.S. de Cachan. 61 avenue du Président Wilson. F-94235 Cachan Cedex. France.

${ }_{+}^{+}$Now at Department of Solid Mechanics. Royal Institute of Technology. S-100 44 Stockholm. Sweden. 
computations. A mesh dependence study is performed and a comparison is made with realistic situations.

\section{LOCALIZATION AND LOSS OF UNIQUENESS}

The failure at a meso-level, i.e. initiation of a macro-crack, is defined as the bifurcation of the rate problem in certain modes, viz. the appearance of a surface across which the velocity gradient is discontinuous (Billardon and Doghri, 1989a). This phenomenon is referred to as localization, and corresponds to the failure of the ellipticity condition (Benallal et al., 1991). The condition of localization can aiso be compared to the loss of uniqueness of the rate problem.

Under small strain assumption and in elasticity coupled with damage, the behavior of a material is assumed to be described by the following piece-wise linear rate constitutive law:

$$
\dot{\Phi}=\left\{\begin{array}{lll}
\mathbb{E}: \dot{\mathbb{E}} & \text { if } & \dot{D}=0, \\
\mathbb{H}: \dot{\mathbb{E}} & \text { if } & \dot{D} \neq 0,
\end{array}\right.
$$

where $\dot{\theta}$ and $\dot{\mathbb{E}}$ respectively denote the stress and strain rates. $\mathbb{E}$ and $\mathbb{H}-\mathbb{H}$ are fourth rank tensors, $\mathbb{E}$ is assumed to be positive definite, and $D$ is either a single damage variable or a set of damage variables.

Localization occurs inside the body, if and only if (Borré and Maier, 1989; Benallal $e t$ al., 1991)

$$
\operatorname{Det}(\mathbf{n} \cdot \mathbb{H} \cdot \mathbf{n})=0, \quad \text { for any vector } \mathbf{n} \neq 0 \text { and at any point inside a structure } \Omega \text {. }
$$

This criterion corresponds to the failure of the ellipicity condition of the rate equilibrium equation (see Appendix A); it can also be used as an indicator of the local failure of the material, i.e. at a meso-scale (Billardon and Doghri, 1989a).

Also, any loss of uniqueness, considered as bifurcation of the rate boundary value problem, is excluded as long as the operator

$$
\mathbb{H}_{s}=\frac{1}{2}\left(\mathbb{H}+\mathbb{H}^{\mathrm{T}}\right)
$$

is strictly positive definite everywhere within the structure. This condition is equivalent to the condition of hardening

$$
\dot{\Phi}: \dot{\varepsilon}>0 \text {. }
$$

In this study, the quantity that defines loss of uniqueness and localization is the linear tangent modulus $\mathbb{H}$. In the following, we analyse loss of uniqueness and loss of ellipticity (i.e. localization) for states when

$$
\left\{\begin{array}{c}
\varepsilon_{11}=\alpha \varepsilon_{22} \text { with } \quad \alpha \in \mathbb{R} \\
\varepsilon_{12}=0
\end{array} .\right.
$$

These particular states only are considered, since we will deal with axisymmetric calculations, which are shear free. These states lead to a tangent modulus that takes the form 


$$
\mathbb{H}=\left[\begin{array}{ccc}
H_{1111} & H_{1122} & 0 \\
H_{2211} & H_{2222} & 0 \\
0 & 0 & H_{1212}
\end{array}\right]
$$

For problems under hypothesis (5), the non-vanishing components of vector $\mathbf{n}$ are $n_{1}$ and $n_{2}$, and the matrix $A=\mathbf{n} \cdot \mathbb{H} \cdot \mathbf{n}$ reduces to (Ortiz et al., 1987)

$$
\mathbb{A}=\left[\begin{array}{cc}
n_{1}^{2} H_{1111}+n_{2}^{2} H_{1212} & n_{1} n_{2}\left(H_{1212}+H_{1122}\right) \\
n_{1} n_{2}\left(H_{1212}+H_{2211}\right) & n_{1}^{2} H_{1212}+n_{2}^{2} H_{2222}
\end{array}\right] .
$$

If we rewrite $\left(n_{1}, n_{2}\right)=(\cos \theta, \sin \theta), X=\tan ^{2} \theta$, then the localization condition is to find real positive roots of the following equation:

$$
a X^{2}+b X+c=0
$$

with

$$
\begin{aligned}
& a=H_{1212} H_{2222}, \\
& b=H_{1111} H_{2222}-H_{1122} H_{2211}-H_{1122} H_{1212}-H_{2211} H_{1212} \\
& c=H_{1212} H_{1111} .
\end{aligned}
$$

If real positive roots are found, then the localization direction is perpendicular to the vector $\left(n_{1}, n_{2}, 0\right)=(\cos \theta \cdot \sin \theta, 0)$, characterized by the angle $\theta$ (Fig. 1$)$.

The values of $H_{1111}, H_{2222}, H_{1122}, H_{2211}$ and $H_{12 ! 2}$ are model-dependent and specific models are now developed.

\section{UNIAXIAL STUDY}

This section is concerned with the development of a single damage variable model for tensile behavior of unidirectional fiber-reinforced ceramic-matrix composites. A schematic

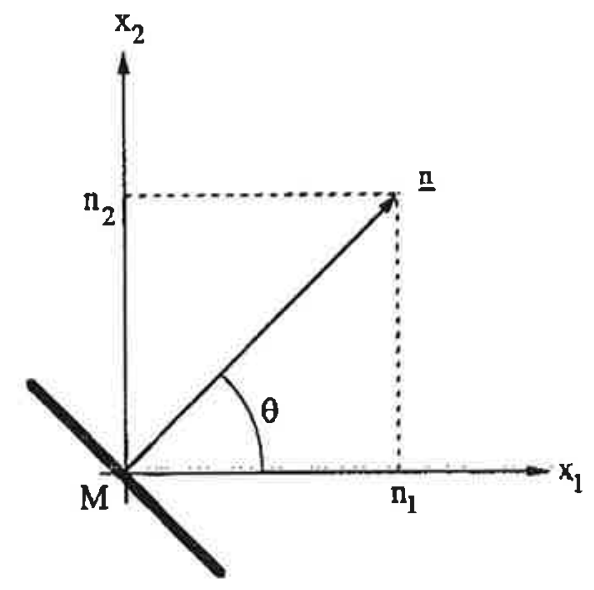

Fig. 1. Localization mode. 


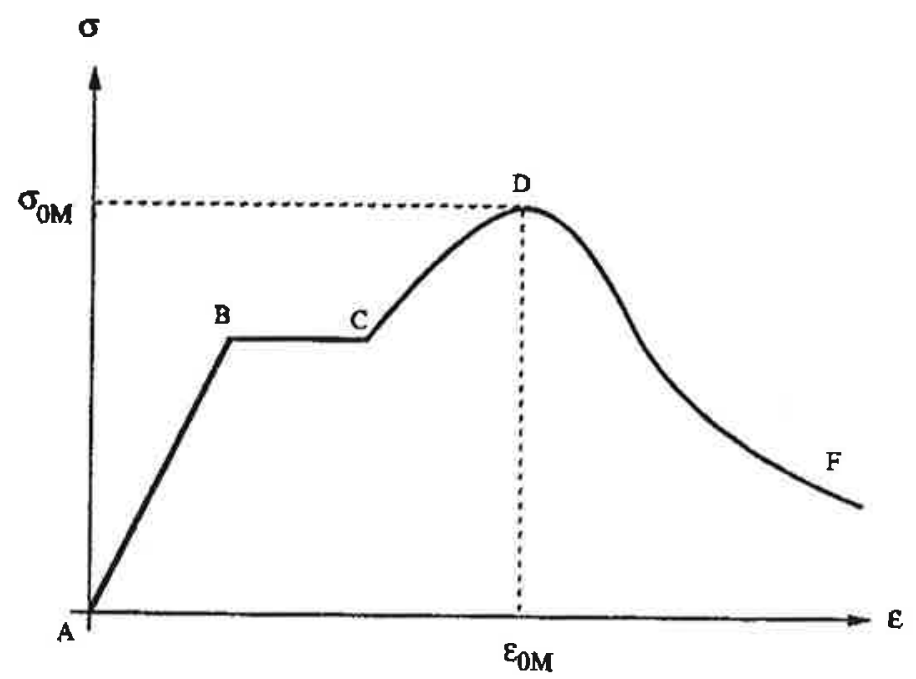

Fig. 2. Schematic uniaxial stress-strain curve [after Hayhurst er al. (1988)].

stress-strain diagram is shown in Fig. 2 for such a specimen. The micro-structural phenomena responsible for the features of curve $A B C D F$ are now discussed. On initial loading from point $A$ to $B$ of Fig. 2 the composite behaves as a virgin, i.e. undamaged. elastic material with modulus $E$. Further loading from point $\mathrm{B}$ to $\mathrm{C}$ causes cracking of the matrix. The cracks traverse the entire load-bearing section within the homogeneousiy stressed region (Hayhurst et al., 1988). Further loading along CDF (Fig. 2) involves further development of matrix cracks, which involves two processes. First the process of fiber debond, both at the front of the crack and in its wake, which is necessary to cause the stresses to redistribute. The second process is fiber failure, which precedes the process of fiber pull-out. It is the iatter, predominantly irreversible process, which absorbs considerable energy and is responsible for giving such materials their toughness and ductility (Hayhurst et al., 1988).

The characteristics of fiber failure are determined by a statistical distribution of fiber strength (Coleman, 1958). This single mechanism is the only one considered in this study. Future development can be carried out by modeling the fiber pull-out mechanism.

The model is based upon the assumption that the nominal stress applied to a bundle of fibers in parallel can be expressed in terms of a damage variable, denoted by $D=r / n$, where $r$ is the number of failed fibers and $n$ is the total number contained within the loadbearing cross-section. This type of approach has been applied to perfectly brittle fiber systems (Krajcinovic and Silva, 1982; Hult and Travnicek, 1983). It is shown that the nominal applied stress $\sigma$ is related to the uniaxial strain $\varepsilon$ by

$$
\sigma=E(1-D) \varepsilon=\tilde{E} \varepsilon
$$

where $E$ is the Young's modulus of each non-broken fiber and $\tilde{E}$ the Young s modulus of the damaged bundle. If the nominal stress is the total current load divided by the total initial fiber area, then the average stress in the unfailed fibers is

$$
\tilde{\sigma}=\frac{\sigma}{1-D}
$$

This later expression refers to the concept of effective stress (Rabotnov, 1963; Lemaitre and Chaboche, 1990). Although the nominal stress does not always increase with the applied strain $\varepsilon$, the stress $\tilde{\sigma}$ in the unfailed fibers does increase whatever the applied strain $\varepsilon$. We assume that the probability of fiber survival at a stress $\tilde{\sigma}$ is given by a Weibull distribution: 


$$
G(\tilde{\sigma})=1-F(\tilde{\sigma})=1-\exp \left[-\frac{V}{V_{m}}\left(\frac{\tilde{\sigma}}{\sigma_{m}}\right)^{m}\right]
$$

where $m$ is the so-called Weibull modulus, $\sigma_{m}$ is a scale parameter and $V_{m}$ is a reference volume (for instance a specimen volume for which $m$ and $\sigma_{m}$ were identified). Therefore the ratio $r / n$ characterized by damage variable $D$ is

$$
r / n=D=G(\tilde{\sigma})
$$

This definition is consistent with the bounded values of $D$ for which $D=0$ for no failed fiber and $D=1$ for complete failure of all fibers.

The damage is therefore related to the nominal stress through relation (11):

$$
D=1-\exp \left[-\frac{V}{V_{m}}\left\{\frac{\sigma}{(1-D) \sigma_{m}}\right\}^{m}\right], \quad \text { if } \quad \varepsilon>0 \text { and } \dot{\varepsilon}>0
$$

or to the uniaxial corresponding strain by

$$
D=1-\exp \left[-\frac{V}{V_{m}}\left(\frac{\varepsilon}{\varepsilon_{m}}\right)^{m}\right], \text { if } \varepsilon>0 \text { and } \dot{\varepsilon}>0
$$

with

$$
\varepsilon_{m}=\sigma_{m} / E
$$

The relationship between the nominal stress $\sigma$ and $\varepsilon$ can be either implicit

$$
\sigma=E \varepsilon \exp \left[-\frac{V}{V_{m}}\left\{\frac{\sigma}{(1-D) \sigma_{m}}\right\}^{m}\right], \quad \text { if } \quad \varepsilon>0 \quad \text { and } \quad \dot{\varepsilon}>0
$$

or explicit

$$
\sigma=E \varepsilon \exp \left[-\frac{V}{V_{m}}\left\{\frac{\varepsilon}{\varepsilon_{m}}\right\}^{m}\right], \quad \text { if } \quad \varepsilon>0 \text { and } \dot{\epsilon}>0
$$

The peak in the stress-strain plane $(\sigma, \varepsilon)$ is given by (Fig. 3)

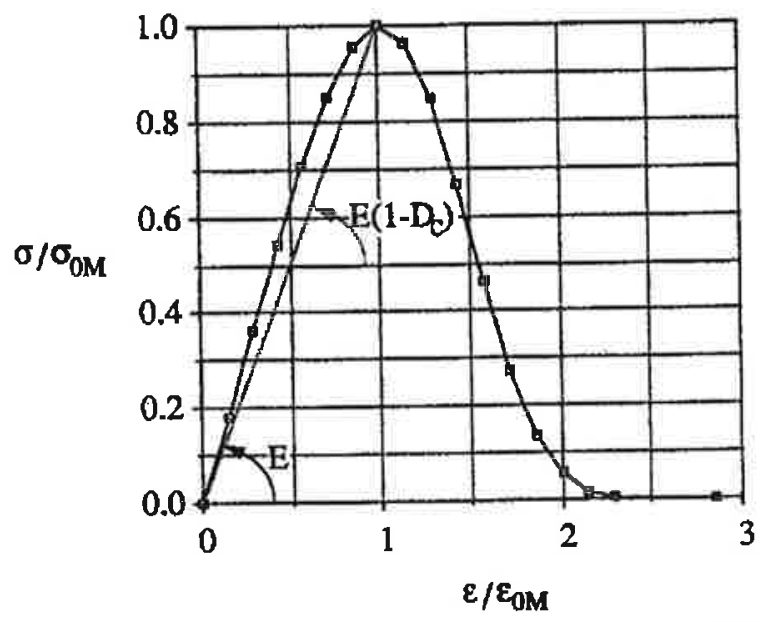

Fig. 3. Normalized stress $\left(\sigma / \sigma_{O M}\right)$ us normalized $\operatorname{strain}\left(\varepsilon / \varepsilon_{O M}\right)$ when $m=4$. 


$$
D=D_{\mathrm{c}}=1-\exp (-1 / m)
$$

It can be noticed that the critical value of the damage is independent of volume $\bar{V}$ of a considered structure $\Omega$. Conversely, the maximal nominal stress $\sigma_{0 \mathrm{M}}$ depends upon volume $V$ :

$$
\sigma_{0 \mathrm{M}}=\sigma_{m}\left(\frac{V_{m}}{m V}\right)^{1 / m} \exp (-1 / m)
$$

The higher the volume, the lower the maximal nominal stress (that is. the strength of the structure). This result agrees with experiments and is known as a volume effect (Weibull, 1939a,b; Coleman, 1958 ; Kadlecek and Spetla, 1967; Davies, 1973 ; Katamaya and Hattori, 1982). The critical value of damage, $D_{\mathrm{c}}$, is only related to the Weibull parameter $m$ by (16) and is therefore a material dependent parameter. Conversely, $\sigma_{0 M}$ depends upon the volume of the considered structure, so that it is not a material parameter.

Finally, as it has been mentioned above, this model does not consider fiber pull-out. Thus this model constitutes a lower bound estimate after the maximal nominal stress is reached, for a strain-controlled test. Indeed, the pull-out mechanism often delays the decrease of the curve $(\sigma, \varepsilon)$ (Hayhurst et al., 1988). If the test is stress-controlled, then the point for which $\sigma=\sigma_{0 \mathrm{M}}$ constitutes the ultimate stable point.

\section{2-D STUDY}

This section deals with the study of a 2-D model extending the ideas of the previous section. The fibers are assumed to be parallel to the 2-direction. In elasticity, under the plane stress hypothesis, with the small strain assumption, the relationship between stresses and strains is given by

$$
\left[\begin{array}{l}
\varepsilon_{11} \\
\varepsilon_{22} \\
\varepsilon_{12}
\end{array}\right]=\left[\begin{array}{ccc}
1 / E_{1} & -v_{21} / E_{2} & 0 \\
-v_{12} / E_{1} & 1 / E_{2} & 0 \\
0 & 0 & 1 / 2 G_{12}
\end{array}\right]\left[\begin{array}{l}
\sigma_{11} \\
\sigma_{22} \\
\sigma_{12}
\end{array}\right] .
$$

When fiber breaking in the 2-direction is considered. the damage state is described by damaged elastic constants $\widetilde{E}_{1}, \widetilde{E}_{2}, \tilde{v}_{12}, \tilde{v}_{21}, \widetilde{G}_{12}$ instead of $E_{1}, E_{2}, v_{12}, v_{21}, G_{12}$, respectively. The Young's modulus $E_{2}$ is no longer constant but depends upon the degradation of the fibers characterized by $D_{2}$ to become $\widetilde{E}_{3}=E_{2}\left(1-D_{2}\right)$ : it is a straightforward extension of relation (10), Since pulling in the 1-direction has no effect on the strains in the 2-direction, $\tilde{v}_{12}$ is constant and equals $v_{12}$. Finally we assume that $\widetilde{E}_{1}=E_{1}$ (no effect of the damage $D$ in the 1-direction) and that $\tilde{G}_{12}=G_{12}$ (the shear properties are slightly altered by fiber failure). We also suppose that the material is hyperelastic so that

$$
\frac{\tilde{\nu}_{21}}{\tilde{E}_{2}}=\frac{\tilde{\nu}_{12}}{\tilde{E}_{1}}
$$

It can therefore be noticed that $\tilde{v}_{2 !}=v_{21}\left(1-D_{2}\right)$ and if $D_{2}=0$ then the behavior is purely elastic and is described by relation (18). This model has a general form very close to the model proposed by Allix et al. (1985). However, the damage evolution is generally different. The relationships between strains and stresses are given by $\left(k=E_{2} / E_{1}\right)$

$$
\begin{aligned}
\sigma_{11} & =\frac{E_{2}}{k\left[1-v_{12}^{2}\left(1-D_{2}\right) k\right]}\left[\varepsilon_{11}+v_{12}\left(1-D_{2}\right) k \varepsilon_{22}\right] \\
\sigma_{22} & =\frac{E_{2}\left(1-D_{2}\right)}{1-v_{12}^{2}\left(1-D_{2}\right) k}\left(\varepsilon_{22}+v_{12} \varepsilon_{11}\right) .
\end{aligned}
$$


As mentioned in Section 2, the damage state of fibers in the 2-direction, $D_{2}$, can be related to the stress or strain state either through an implicit relationship for model No. 1 $\left(D_{2 t}\right)$ :

$$
D_{21}=1-\exp \left[-\frac{V}{V_{m}}\left\{\frac{\sigma_{22}}{\left(1-D_{21}\right) \sigma_{m}}\right\}^{m}\right], \quad \text { if } \quad \varepsilon_{22}>0 \text { and } \dot{\varepsilon}_{22}>0
$$

or through an explicit relationship for model No, $2\left(D_{22}\right)$ :

$$
D_{22}=1-\exp \left[-\frac{V}{V_{m}}\left\{\frac{\varepsilon_{22}}{\varepsilon_{m}}\right\}^{m}\right], \text { if } \varepsilon_{22}>0 \text { and } \dot{\varepsilon}_{22}>0 \text {. }
$$

Both models describe the material behavior when subjected to uniaxial tension. However the models give different predictions for multiaxial loading states. It is worth noting that the stress $\sigma_{m}$ depends upon the fiber volume fraction, whereas the strain $\varepsilon_{m}$ is still independent of the fiber volume fraction.

\subsection{Model No. 1}

For model No. 1 the tangent operator takes the form:

$$
\begin{aligned}
& H_{1111}=F_{1}-\frac{F_{2} F_{4} F_{7}}{1+F_{5} F_{7}}, \\
& H_{2212}=\frac{F_{6}}{1+F_{5} F_{7}}, \\
& H_{1122}=H_{2211}=v_{12} H_{2222}, \\
& H_{1212}=2 G_{12},
\end{aligned}
$$

where the explicit expressions for $F_{i}$ are given in Appendix B.

Also, it can be noticed that if $D_{21}=D_{\mathrm{c}}$ then $F_{7}$ tends to infinity. Therefore $H_{1122}$, $H_{2211}$ and $H_{2222}$ vanish simultaneously and $H_{1111}, H_{1212}$ are strictly positive. This point corresponds to the loss of uniqueness and to a localization with $\theta=\pi / 2$ (i.e. perpendicular to the fiber direction). It can be proven that $D_{21}=D_{\mathrm{c}}$ (viz. $H_{2222}=0$ and therefore $H_{1122}=H_{2211}=0$ ) constitutes a necessary and sufficient condition for loss of uniqueness and localization. An initiation criterion can therefore be (Fig. 4)

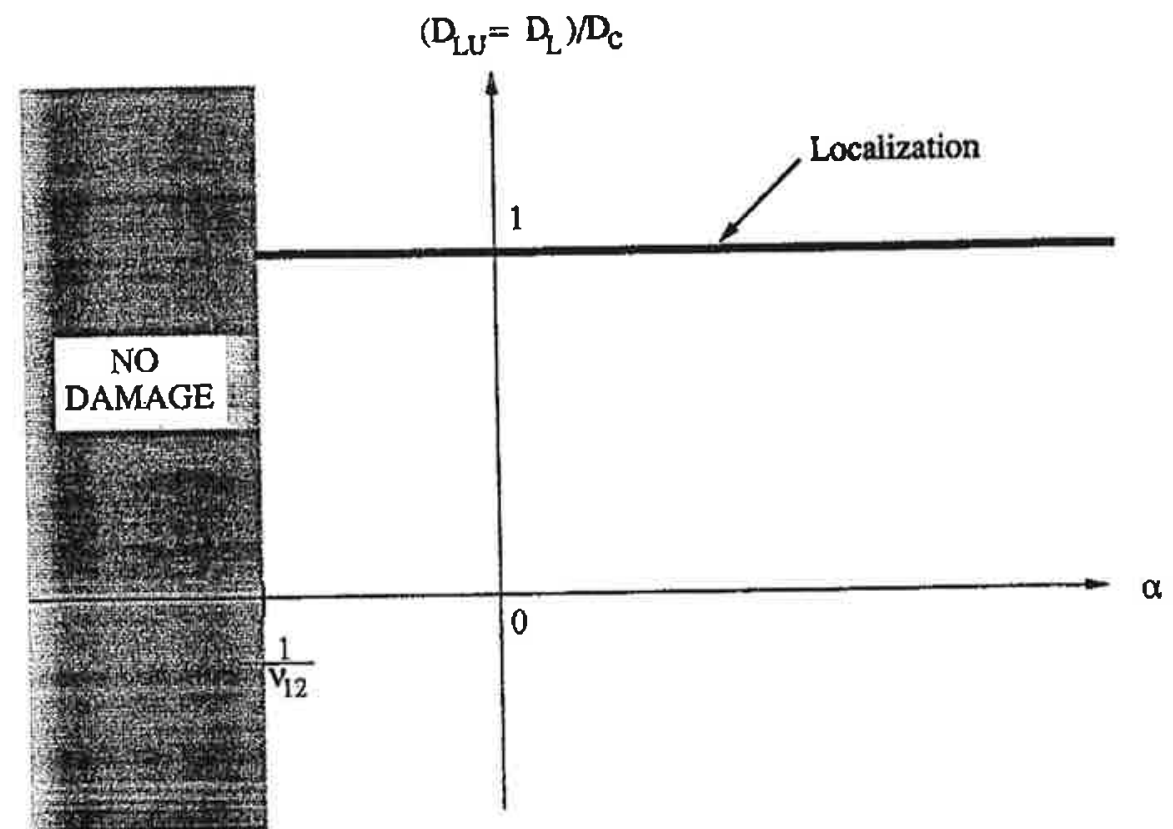

Fig. 4. Normalized damage at loss of uniqueness $\left(D_{\mathrm{Lu}} / D_{\mathrm{c}}\right)$ and localization $\left(D_{\mathrm{L}} / D_{\mathrm{c}}\right)$ vs strain ratio $\alpha$ for model No. 1 . 


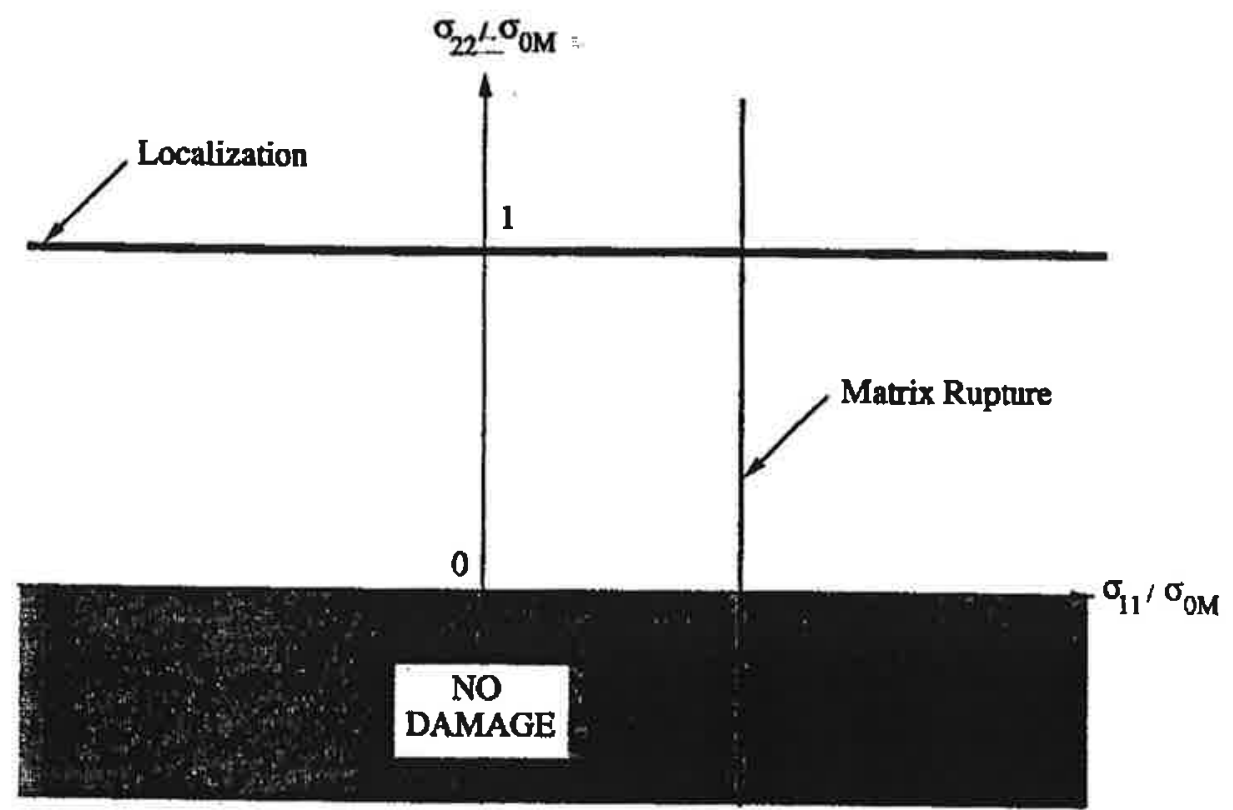

Fig. 5. Normalized stress level at loss of uniqueness and localization in the fiber direction $\left(\sigma_{22} / \sigma_{0 M}\right)^{-1}$ against the corresponding stress perpendicular to the fiber direction $\left(\sigma_{1,} / \sigma_{0 M}\right)$.

$$
D_{21}=D_{\mathrm{c}}
$$

Since the condition (22a) implies that $\sigma_{22}$ [see relation (20c)] is constant and equals $\sigma_{0 \mathrm{M}}$, another criterion may be (Fig. 5)

$$
\sigma_{22}=\sigma_{0 \mathrm{M}}
$$

It can also be shown that the criterion (22b) can be expressed in terms of the strain energy release rate density $Y$ (Lemaitre and Chaboche, 1990), reaching a critical value $Y_{\mathrm{c}}$;

$$
Y=Y_{\mathrm{c}}=\frac{1}{2} \frac{\sigma_{0 \mathrm{M}}^{2}}{E_{2}\left(1-D_{\mathrm{c}}\right)^{2}}
$$

where $Y=\rho\left(\partial \psi_{1} / \partial D_{21}\right), \rho \psi_{1}\left(\sigma, D_{21}\right)$ is the strain energy density, which is a function of the Cauchy's stress tensor $\sigma$, and the damage variable $D_{21}, \rho$ denotes the material density, here assumed to be constant. The strain energy density $\rho \psi_{1}$ takes the form

$$
\rho \psi_{1}=\frac{1}{2}\left[\frac{\sigma_{11}^{2}}{E_{1}}-\left(\frac{\nu_{12}}{E_{1}}+\frac{\nu_{21}}{E_{2}}\right) \sigma_{11} \sigma_{22}+\frac{\sigma_{12}^{2}}{G_{12}}+\frac{\left\langle-\sigma_{22}\right\rangle^{2}}{E_{2}}+\frac{\left\langle\sigma_{22}\right\rangle^{2}}{E_{2}\left(1-D_{21}\right)}\right],
$$

where $\langle\cdot\rangle$ denotes McCauley's brackets: $\langle\cdot\rangle=\frac{1}{2}[(\cdot)+|\cdot|]$.

Moreover, criterion (22b) can be rewritten in terms of $\varepsilon_{22}$ (Fig. 6) by using relation (20b) and yields

$$
\varepsilon_{22}\left(1+\alpha v_{12}\right)=\varepsilon_{0}
$$

where $\varepsilon_{0}$ corresponds to the localization strain when $\alpha=0$.

The localization angle, as expected, is equal to $\pi / 2$ (viz. a localization mode perpendicular to the fiber direction) whatever the strain ratio $\alpha$ (Fig. 7).

It is worth noting that if the failure of the matrix is considered, then localization cannot always occur : there exists another limit given by, for instance, the criterion $\sigma_{11}=\sigma_{M}$, where $\sigma_{\mathrm{M}}$ is the strength of the matrix (see Fig. 5) in the transverse direction.

Knowing the analytical results, it is interesting to study the numerical sensitivity of the detection of the localization point (and therefore the loss of uniqueness as well). The 


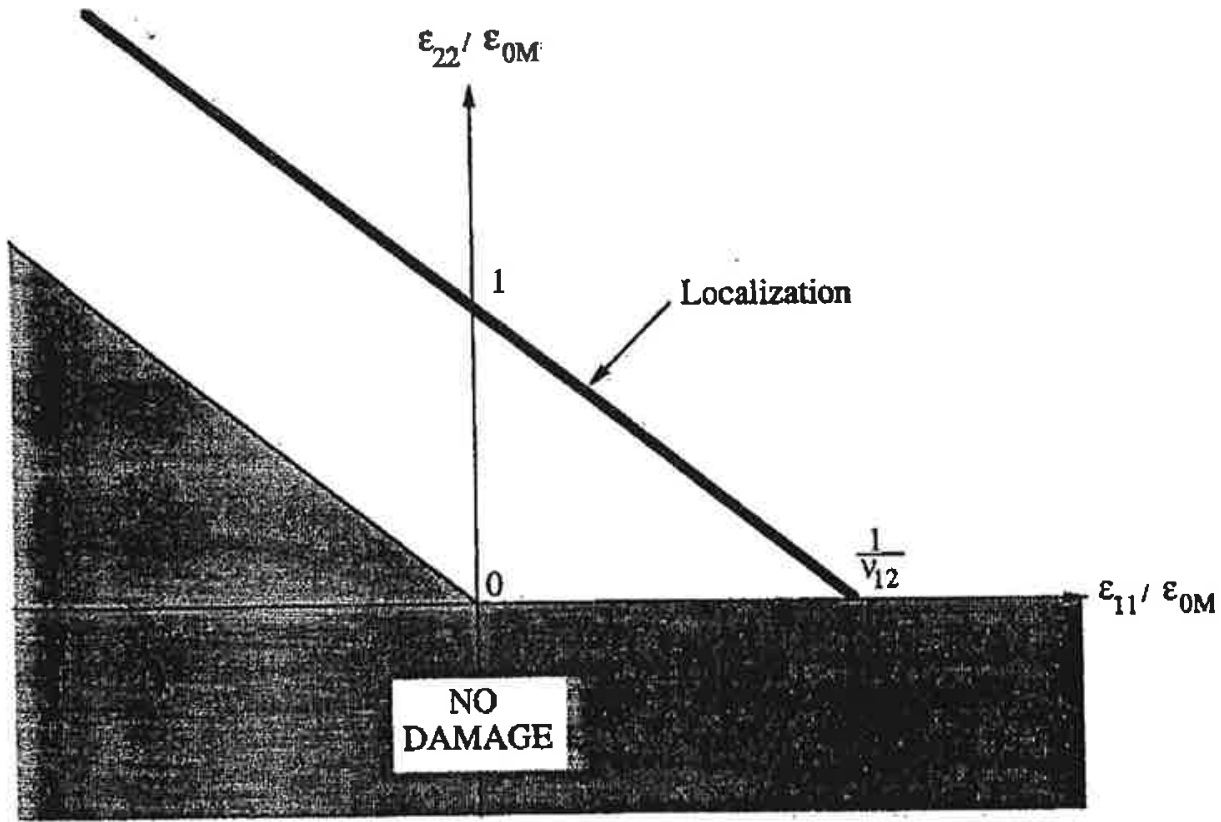

Fig. 6. Loss of uniqueness and localization in $\left(\varepsilon_{1}-\varepsilon_{1}\right)$ plane.

convergence in terms of the damage is rapid compared to the convergence in terms of the direction of localization (Fig. 8(a)). This phenomenon can also be observed in Fig. 8(b). To get accurate information in terms of the damage at localization, direction of localization and stress at localization. it is necessary to be as close as possible to the actual localization state. This trend has also been observed when using a F.E.M. code to compute some more complicated situations. These trends are very close to observations drawn from the study of buckling where the detection also has to be as accurate as possible.

In summary, model No. 1 leads to some very simple results. First, loss of uniqueness and localization occur simultaneously. Second, some very simple criteria (22) can be derived from criteria (2) and (3), and show that the relevant parameters are Weibull's parameter $m$ and Poisson's ratio $v_{12}$. Third, the results are independent of the Young's modulus ratio $k=E_{2} / E_{1}$. Fourth. whatever the strain ratio $\alpha$, the direction of localization is constant and perpendicular to the fiber direction. This model gives the same results as those found in a uniaxial approach and constitutes a straightforward generalization to 2-D cases. From a

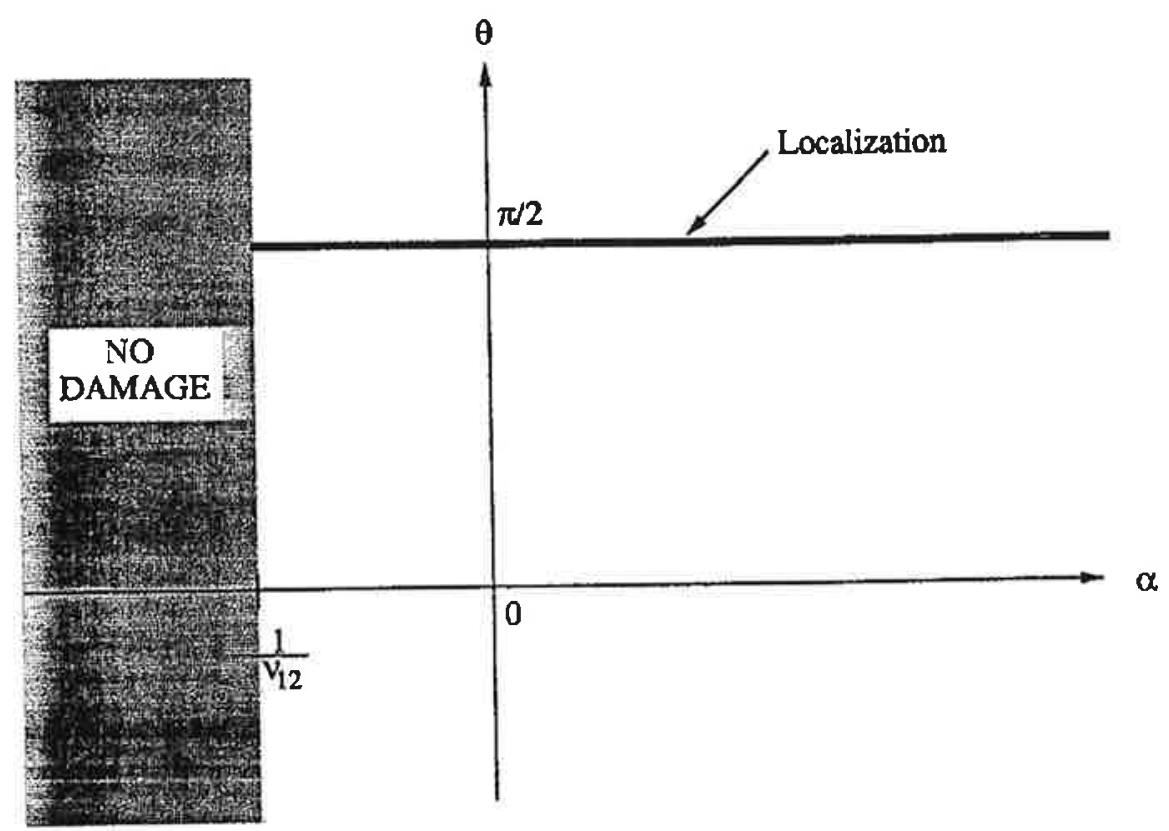

Fig. 7. Localization direction $(\theta)$ vs strain ratio $(\alpha)$. 
$\theta\left(^{\circ}\right)$

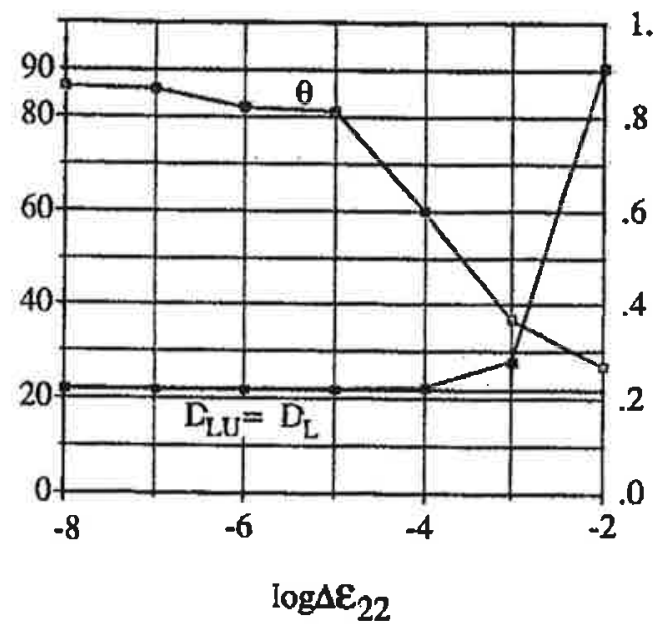

$\mathrm{D}_{\mathrm{LU}}=\mathrm{D}_{\mathrm{L}}$

Fig. 8 (a). Damage at localization $\left(D_{\mathrm{L}}\right)$ and at loss of uniqueness $\left(D_{\mathrm{Lv}}\right)$, direction of localization ( $\theta$ ) for different increments of deformation $\left(\Delta \varepsilon_{22}\right)$ when $\alpha=0$.

$\theta\left(^{\circ}\right)$

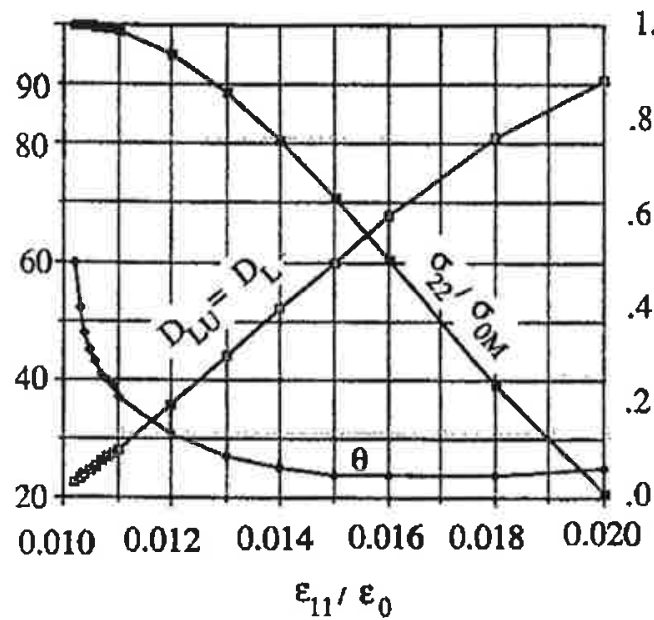

$$
\begin{aligned}
& \sigma_{22} / \sigma_{0 \mathrm{M}} \\
& \mathrm{D}_{\mathrm{LU}}=\mathrm{D}_{\mathrm{L}}
\end{aligned}
$$

$$
\varepsilon_{11} / \varepsilon_{0}
$$

Fig. 8 (b). Damage at localization $(D)$, angle at localization $(\theta)$ and normalized stress at localization $\left(\sigma_{23} / \sigma_{0 \mathrm{M}}\right)$ vs nomalized strain in the fiber direction $\left(\varepsilon_{2 y}, \varepsilon_{0}\right)$ when $x=0$.

numerical standpoint, it is important to be as close as possible to the localization point to get accurate information.

\subsection{Model No. 2}

The tangent operator for model No. 2 takes the form

$$
\begin{aligned}
& H_{1111}=F_{1}, \\
& H_{2222}=F_{6}-F_{5} F_{3}, \\
& H_{1122}=F_{4}-F_{2} F_{3}, \\
& H_{2211}=F_{4}, \\
& H_{1212}=2 G_{12},
\end{aligned}
$$

where the explicit expressions for $F_{i}$ are given in Appendix B.

It may be noticed that the tangent operator does not possess the same remarkable properties as those exhibited by model No. 1. In particular, the previous necessary and sufficient conditions do not apply. Indeed, the relationship between the damage variable $D_{21}$ of model No. 1 and the damage variable $D_{22}$ of model No. 2 is given by using relations (20): 


$$
D_{22}=1-\exp \left[\left(\frac{1-v_{12}^{2}\left(1-D_{21}\right)}{1+\alpha v_{12}}\right)^{m} \ln \left(1-D_{21}\right)\right], \quad \text { if } \quad \varepsilon_{22}>0 \text { and } \dot{\varepsilon}_{22}>0
$$

On the other hand, the strain energy density takes the form for model No. 2 :

$$
\rho \psi_{2}=\frac{1}{2}\left[\frac{\sigma_{11}^{2}}{E_{1}}-\left(\frac{\nu_{12}}{E_{1}}+\frac{\nu_{21}}{E_{2}}\right) \sigma_{11} \sigma_{22}+\frac{\sigma_{12}^{2}}{G_{12}}+\frac{\left\langle-\sigma_{22}\right\rangle^{2}}{E_{2}}+\frac{\left\langle\sigma_{22}\right\rangle^{2}}{E_{2}\left(1-D_{22}\right)}\right]
$$

and can be rewritten in terms of $D_{2 L}$ by using relation (24):

$$
\begin{aligned}
\rho \psi_{2}=\frac{1}{2}\left[\frac{\sigma_{11}^{2}}{E_{1}}-\left(\frac{\nu_{12}}{E_{1}}+\frac{\nu_{21}}{E_{2}}\right) \sigma_{11} \sigma_{22}\right. & +\frac{\sigma_{12}^{2}}{G_{12}}+\frac{\left\langle-\sigma_{22}\right\rangle^{2}}{E_{2}} \\
& +\frac{\left\langle\sigma_{22}\right\rangle^{2}}{\left.E_{2} \exp \left[\left(\frac{1-v_{12}^{2}\left(1-D_{21}\right) k}{1+\alpha v_{12}}\right)^{m} \ln \left(1-D_{21}\right)\right]\right]} .
\end{aligned}
$$

From an energetic viewpoint, the two models are different as shown in Fig. 9 for a uniaxial case $\left(\sigma_{11}=\sigma_{12}=0\right)$. For model No. 1 , the strain energy density only depends upon $D_{21}$, whereas for model No. 2 , the strain energy density depends upon $D_{22}$ but also upon $k, \alpha$ and $v_{12}$. Therefore the two models are completely different.

This difference can also be highlighted by the study of localization and loss of uniqueness. Whereas the loss of uniqueness and the localization can be characterized by very simple criteria for model No. 1 , it is no longer the case for model No. 2. First, the results in terms of damage at localization $D_{22}$ (Fig. 10), of strain $\varepsilon_{22}$ (Fig. 11) and of stress $\sigma_{22}$ (Fig. 12) are no longer independent of the strain ratio $\alpha$. Furthermore, the quantities $D_{22}$, $\varepsilon_{22}$ and $\sigma_{22}$ at localization (Fig. 13) depend upon the Young's moduli ratio $k$. Instead of having one localization angle (model No. 1), model No. 2 leads to two localization angles, which vary with $\alpha$ and $k$ (Fig. 14). The same criteria as those used for model No. 1 do not apply and no straightforward criterion seems to apply.

Although derived from the same uniaxial analysis, models No. 1 and No. 2 lead to different results when applied under plane stress conditions. Whereas loss of uniqueness and localization can very simply be described for model No. 1, model No. 2 does not admit such simple descriptions. Moreover, loss of uniqueness and localization do not occur for

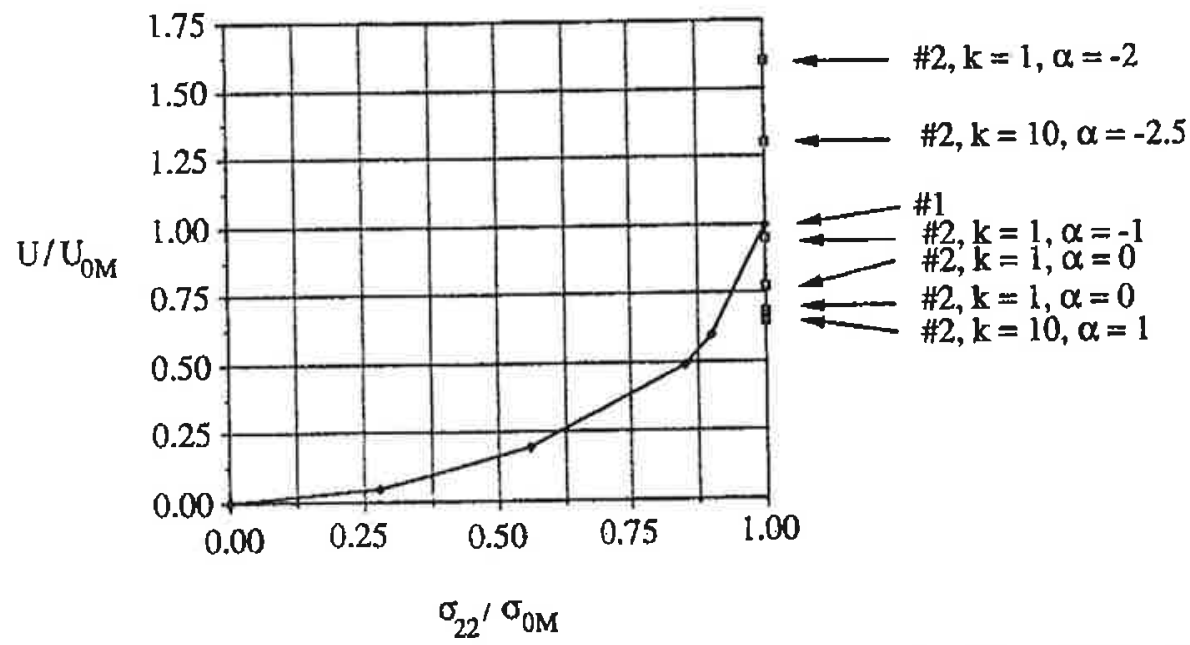

Fig. 9. Normalized strain energy vs normalized stress in the fiber direction for model No. $I$ and model No. 2. 


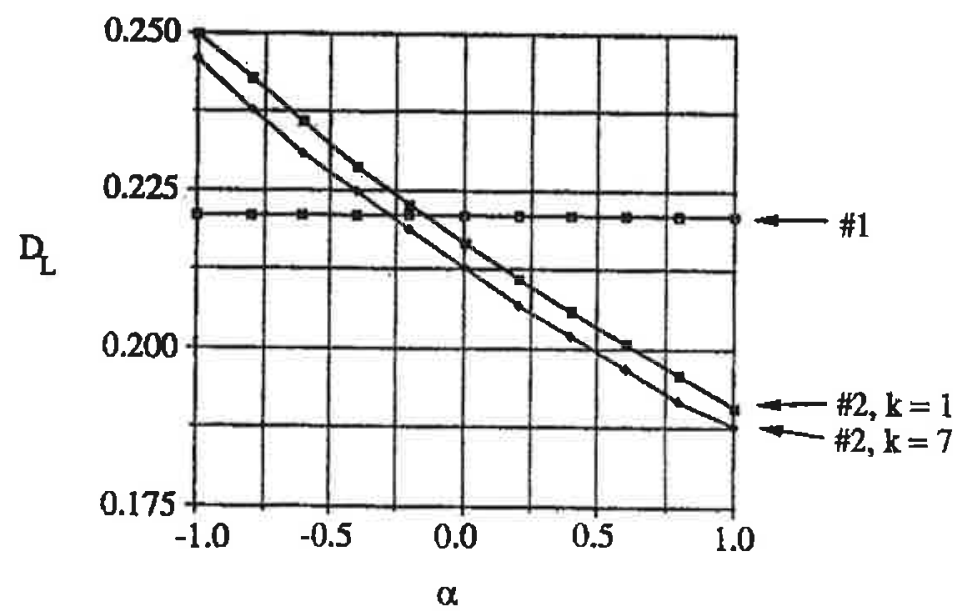

Fig. 10. Damage at localization vs strain at localization for model No. 1 and model No. 2 when $\alpha$ ranges from -1 to $+1(k=1,7)$.

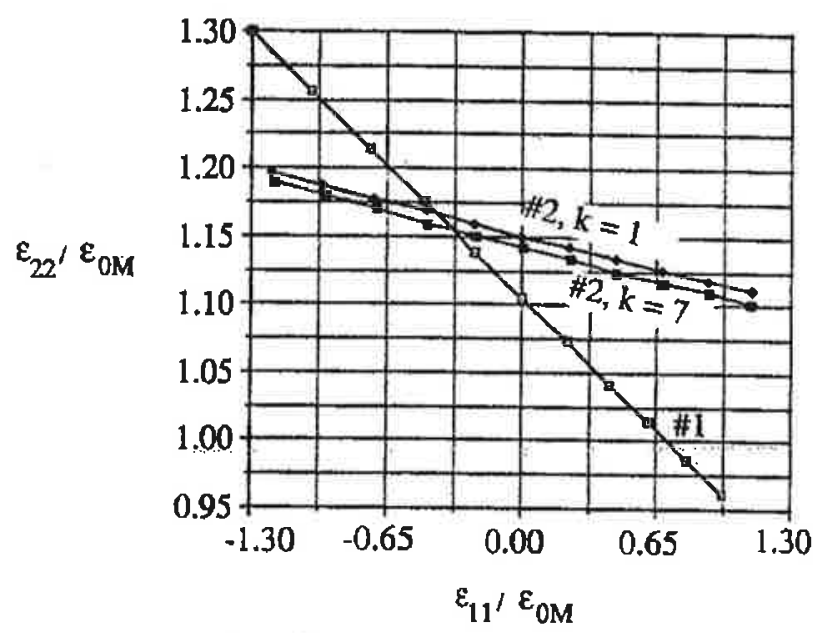

Fig. 11. Strains at localization for model No. 1 and model No, 2 when $\alpha$ ranges from -1 to +1 .

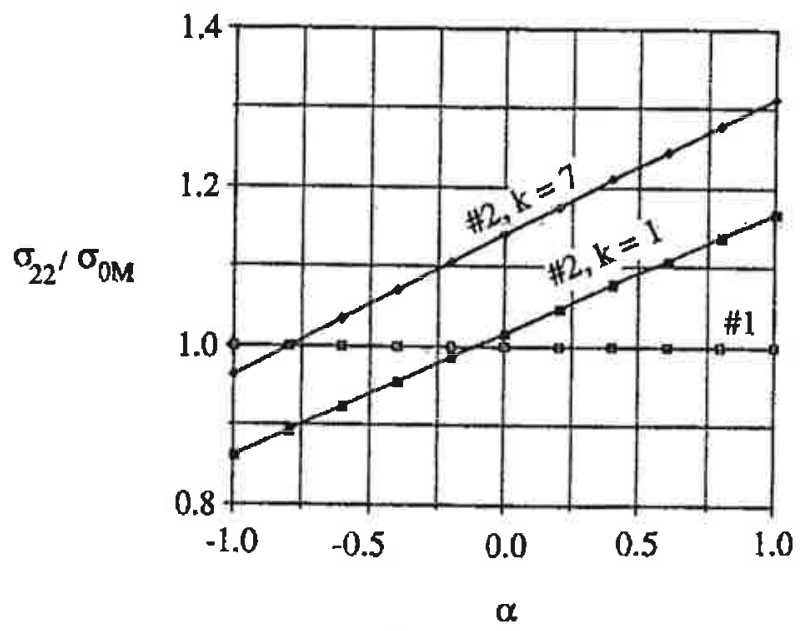

Fig. 12. Stress in the fiber direction at localization vs strain ratio $x$ for model No. 1 and model No. 2.

the same load level. Nevertheless the two load levels are very close together (as will be shown in the next section).

These results show that a straightforward generalization from unidimensional models to two-dimensional problems can lead to different types of results. A way to choose the most realistic one is to perform experiments. 


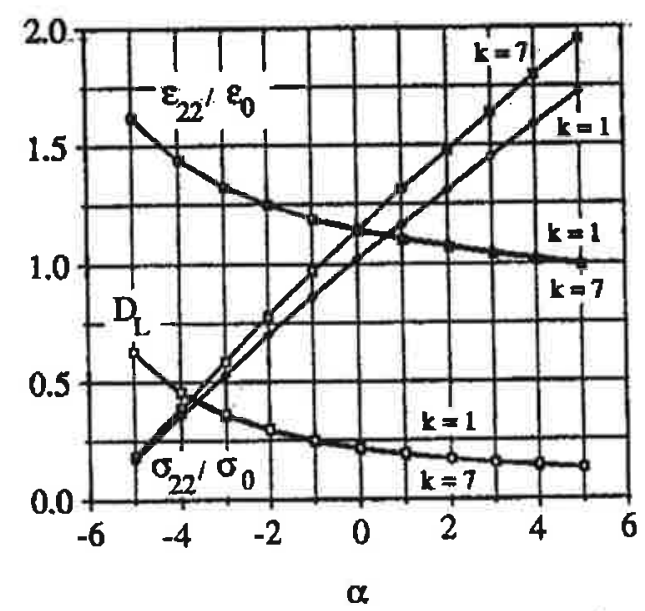

Fig. 13. Strain, stress in the fiber direction and damage at localization for model No. $2(k=1,7)$ for different strain ratios $(\alpha)$.

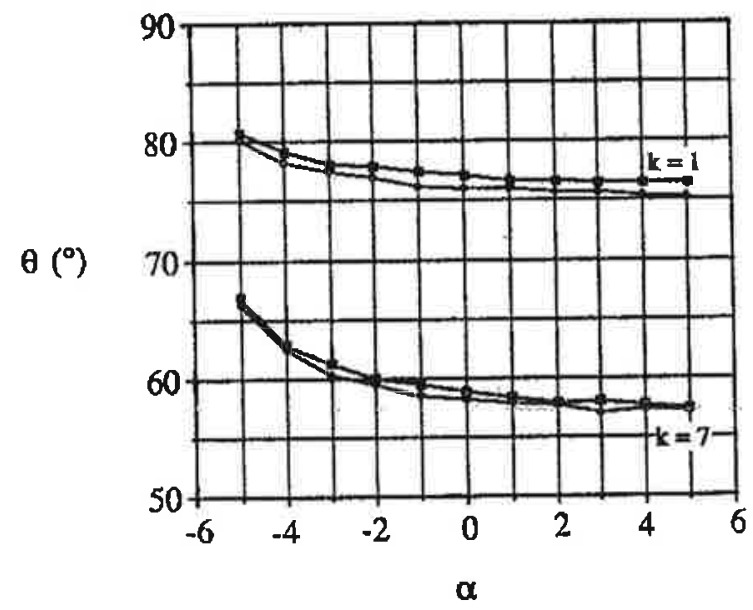

Fig. 14. Localization angle vs strain ratio $\alpha$ for model No. 1 and model No. $2(k=1,7)$.

\section{F.E.M. ANALYSIS: SPINNING DISC}

A problem that is given special attention is the case of a circular disc made out of a fiber composite material. The analysis of this problem is performed not only due to its significant practical importance in, for example, turbines, but also due to the presence of a non-homogeneous stress state, a feature that distinguishes this problem from the 2-D study performed above.

The geometry of the problem is shown in Fig. 15. Here $\omega$ represents the angular rotation speed, with dimension $\mathrm{rad} \mathrm{s}^{-1}$. The outer boundary of the disc, $r=a$, is assumed to be free from kinematic constraints and accordingly the loading can be considered here as stress controlled.

In the present setting, the stress state is axisymmetric, at least up to the point where localization occurs, and hence a cylindrical coordinate system is introduced in Fig. 15. If it is assumed that the fibers are oriented in the circumferential direction and coordinates $x_{1}$ and $x_{2}$ in the previous section are replaced with $r$ and $\varphi$ respectively, then the constitutive equations become

$$
\begin{aligned}
\sigma_{r} & =\frac{E_{\varphi}}{k\left[1-v_{r \varphi}^{2}\left(1-D_{\varphi}\right) k\right]}\left[\varepsilon_{r}+v_{r \varphi}\left(1-D_{\varphi}\right) k \varepsilon_{\varphi}\right], \\
\sigma_{\varphi} & =\frac{E_{\varphi}\left(1-D_{\varphi}\right)}{1-v_{r \varphi}^{2}\left(1-D_{\varphi}\right) k}\left(\varepsilon_{\varphi}+v_{r \varphi} \varepsilon_{r}\right),
\end{aligned}
$$




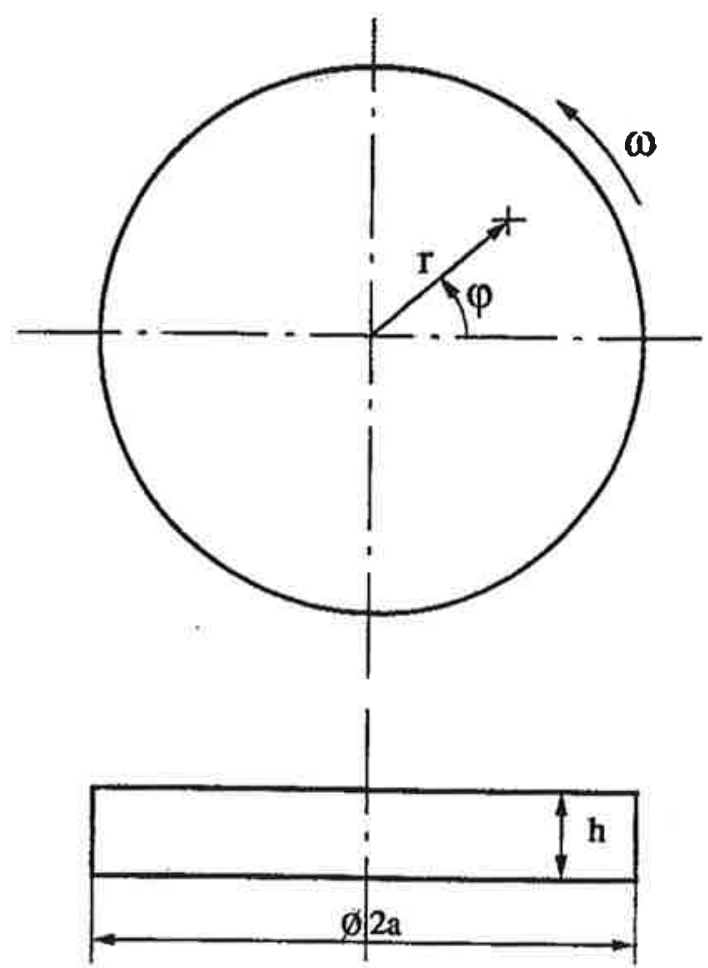

Fig. 15. The circular disc.

in obvious notations. It should be remembered that no shear stress $\sigma_{r \varphi}$ is present due to axisymmetry. The expression for the damage parameter $D_{\varphi}$ is in this problem given by

$$
D_{\varphi \mathrm{I}}=1-\exp \left[-\frac{r}{r_{m}}\left\{\frac{\sigma_{\varphi}}{\left(1-D_{\varphi 1}\right) \sigma_{m}}\right\}^{m}\right], \quad \text { if } \quad \varepsilon_{\varphi \varphi}>0 \text { and } \dot{\varepsilon}_{\varphi \varphi}>0
$$

for model No. $l$ and by

$$
D_{\varphi 2}=1-\exp \left[-\frac{r}{r_{m}}\left(\frac{\varepsilon_{\varphi}}{\varepsilon_{m}}\right)^{m}\right], \text { if } \quad \varepsilon_{\varphi \varphi}>0 \text { and } \dot{\varepsilon}_{\varphi \varphi}>0
$$

for model No. 2. In relations (28), $r_{m}$ is a material constant representing the volume dependence of the problem, while all the other parameters are defined earlier.

To describe completely the axisymmetric boundary value problem, small strain kinematics and equilibrium equations also have to be introduced. At this stage, it proved impossible to derive a closed-form solution for the stress state and for the damage variable. Instead the problem was solved using the finite element method. Constitutive relations (27) and (28) were implemented into a standard finite element code ABAQUS (1989), and a solution was sought by discretizing the problem using 2-node axisymmetric shell elements. Since the linear tangent modulus $\mathrm{H}$ also had to be implemented into the finite element code, the load, or angular rotation speed, required for loss of uniqueness and localization could be conveniently calculated using ABAQUS through a UMAT routine. The conditions for these phenomena to occur were previously discussed and will not be dwelt upon further in this section.

It should be noted that due to the non-explicit expression for the damage parameter given in (28a) an iterative procedure had to be outlined to determine the damage state characterized by $D_{\varphi}$ every time the calculated strain field did change at a certain Gauss point. This was done by using a standard bisection method and should not in any way be a problem regarding the accuracy of the solution.

The finite element procedure, as described, was checked by analysing the problem of a thin walled pressure vessel and a thin rotating ring. Then, the stress state can be derived 
in a closed form through the equilibrium equations and comparisons between the analytical and the finite element results were possible. Without going into details, excellent agreement was found between the two solutions, a fact that gives confidence in the numerical procedure outlined above.

A test of mesh dependence of the numerical resuits is also performed. The number of elements proves to have a very weak infiuence on the solution and satisfactory results for the stress and state variable can be obtained by modeling the disc with only 20 elements.

Before focusing attention on explicit results, one should first mention that the nonhomogeneity of the stress field in this axisymmetric problem did not in any way change the important features of the mechanical (damage) behavior. All the conclusions drawn in the 2-D study are essentially confirmed. Therefore, it seems appropriate merely to comment on some numerical results derived from the finite element computations.

In Fig. 16, the engineering stress is plotted as a function of the strain at the point within the rotating disc where loss of uniqueness and localization first occur. The material analysed herein is a ceramic-matrix composite defined in Appendix $\mathrm{C}$, and the geometry of the disc is chosen with practical applications in mind, namely $a=0.3 \mathrm{~m}$ and $h=0.01 \mathrm{~m}$. For model No. 1, localization and loss of uniqueness occur at the same value of $\omega$ and where $r$ has the approximate value $0.248 \mathrm{~m}$. Other critical values of important parameters are

$$
\begin{aligned}
\rho \omega^{2} & =0.58598010^{10} \mathrm{~kg} \mathrm{~m}^{-3} \mathrm{~s}^{-2} \\
D_{\varphi 1} & =0.221199
\end{aligned}
$$

where especially the value of $D_{a p}$ gives further confidence in the numerical procedure since the critical value of the damage was previously proven [see relations (16) and (22a) when $m=4]$ to be $1-\exp (-1 / 4)=0.2211992 \ldots$

The direction of localization coincides with the direction perpendicular to the fiber direction, as already shown analytically. To find the actual value of the localization direction, the point at localization has to be determined with high accuracy, as mentioned in the 2-D study.

Regarding model No. 2, the earlier finding that loss of uniqueness occurs slightly before localization is confirmed by the finite element computation. Yet, the analysis shows that both events take place at the same point, i.e. for the same value of the radius $(r=0.263$ $\mathrm{m})$. Critical values as regards loss of uniqueness are

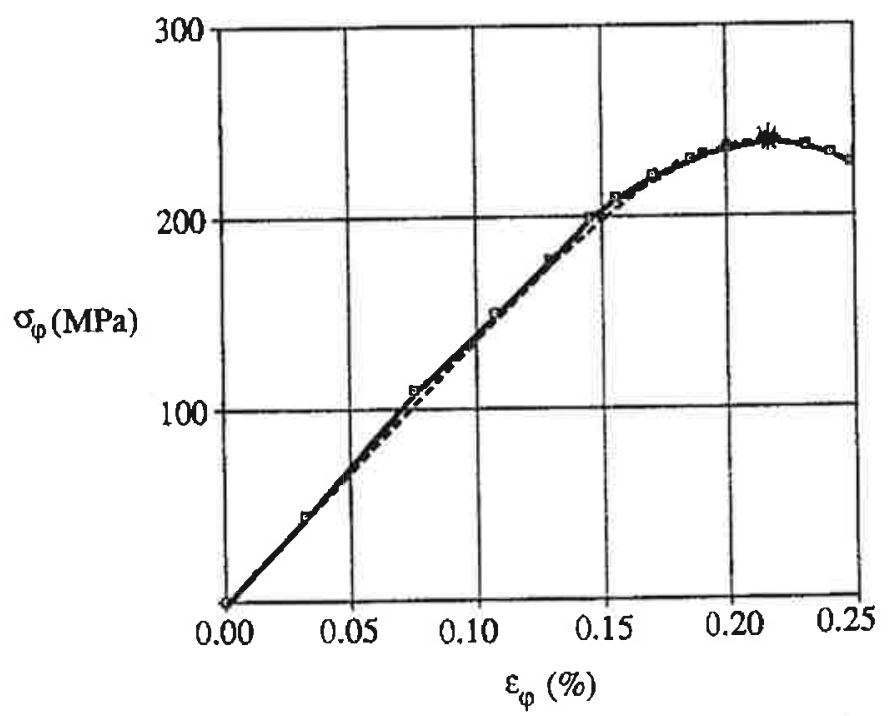

Fig. 16. Engineering stress $\sigma_{\vartheta}$ as a function of strain $\varepsilon_{i q}$ at the point on the circular disc where loss of uniqueness and localization occur. $E=20 \mathrm{GPa} . E_{\sigma}=140 \mathrm{GPa}, v_{s}=0.02143 . G_{r s}=13.0 \mathrm{GPa}$, $m=4, \sigma_{m}=1453 \mathrm{MPa} . r_{m}=0.002 \mathrm{~m} . a=0.3 \mathrm{~m} . h=0.01 \mathrm{~m}$. ( - damage model No. $\mathrm{l}(r=0.248$ $\mathrm{m}),(--)$ damage model No. $2(r=0.263),\left({ }^{*}\right)$ point on the stress-strain curve indicating that loss of uniqueness and localization occurred. 


$$
\begin{aligned}
& \rho \omega^{2}=0.59712010^{10} \mathrm{kgm}^{-3} \mathrm{~s}^{-2}, \\
& D_{\varphi 2}=0.217816
\end{aligned}
$$

and for localization

$$
\begin{aligned}
\rho \omega^{2} & =0.59712210^{10} \mathrm{~kg} \mathrm{~m}^{-3} \mathrm{~s}^{-2} \\
D_{\varphi 2} & =0.217822 .
\end{aligned}
$$

For this model, the direction of localization formed an approximate angle $\pm 14^{\circ}$ with the $r$-axis, which implies that the axisymmetric analysis is no longer valid after localization.

In Fig. 17, the stress field is plotted as a function of the radial coordinate $r$ at $\rho \omega^{2}=0.55$ $10^{10} \mathrm{~kg} \mathrm{~m}^{-3} \mathrm{~s}^{-2}$, that is just before localization. A comparison is made with an elastic solution where the effect of damage is ignored. As might be expected, the introduction of damage reduces the maximum stress acting within the disc.

Though no methodical attempt was made to analyse the stability behavior of the disc, some calculations were performed with model No. 1, under axisymmetric conditions, in the "post localization" region. In this case, the material behavior is assumed still to be described by constitutive equations (27) and (28). This computation constitutes the so-called homogeneous response of the structure since no new constitutive law is introduced in the localization band. It can be noticed that no fiber pull-out effects are considered after localization. The finite element results can therefore be described as a lower bound to the real solution. The calculations show that the additional load, represented by $\rho \omega^{2}$, required for instability proves to be only a few percent of the localization load. This finding is significant from a practical point of view since the load required for loss of uniqueness and localization is very close to load levels reached during service in turbines for example. It may be remembered, as mentioned earlier, that a phenomenon such as fiber pull-out may significantly increase the load-carrying capacity of a structure, as shown by Hayhurst et al. (1988).

\section{CONCLUSIONS}

Using a one-dimensional study of fiber breaking modeled by a single damage variable, two models are derived. Both of them are then generalized to a 2-D plane stress analysis, and differ from an energetic point of view. Whereas model No. 1 constitutes a straightforward

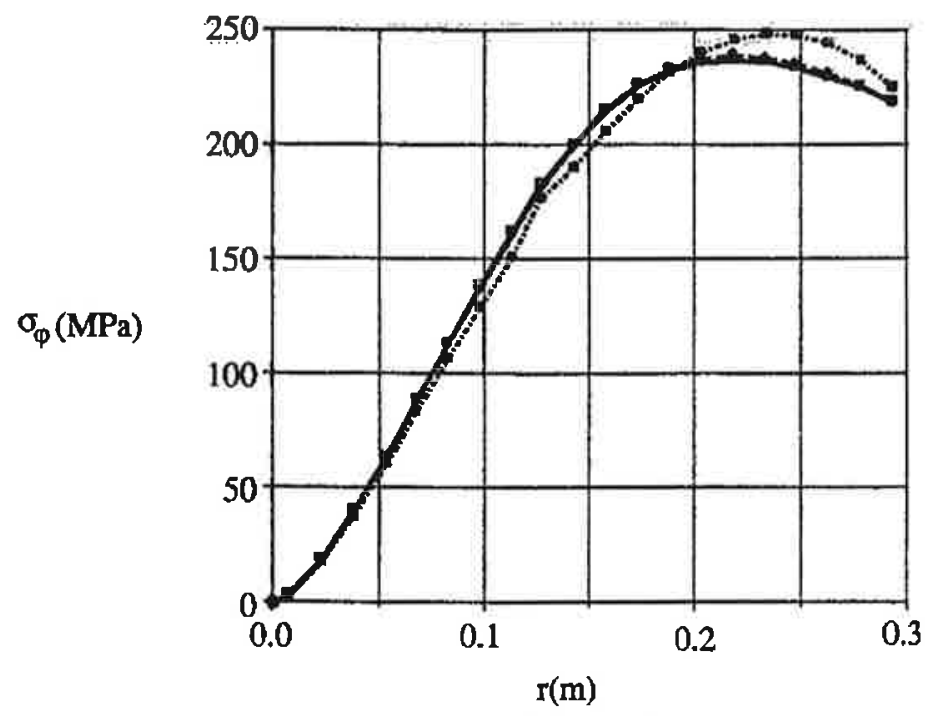

Fig. 17. Engineering stress $\sigma_{\omega}$ as a function of the radial coordinate $r_{.} E_{r}=20 \mathrm{GPa} . E_{\varphi}=140 \mathrm{GPa}$, $v_{r \omega}=0.02143, G_{r \varphi}=13.0 \mathrm{GPa}, m=4, \sigma_{m}=1453 \mathrm{MPa}, r_{m}=0.002 \mathrm{~m}, a=0.3 \mathrm{~m}, h=0.01 \mathrm{~m}$. $\rho \omega^{2}=0.5510^{10} \mathrm{~kg} \mathrm{~m}^{-3} \mathrm{~s}^{-2} .(\underset{-}{)})$ damage model No. $1,(-\rightarrow)$ damage model No. $2,(-\cdot-\cdot)$ linear elastic model when $D_{\varphi}=0$. 
generalization of the elementary study, model No. 2 exhibits different features. Indeed, loss of uniqueness and localization can be described by some very simple criteria referring to Continuum Damage Mechanics for model No. 1. Conversely, these simple criteria do not appiy for model No. 2. This study shows, if necessary, that an identification that seems to be equivalent in an unidimensional analysis can differ significantly in a two-dimensional study. An experimental analysis may decide which model is closer to reality, especially the prediction of the direction of localization.

The conclusions drawn from the 2-D study are essentially confirmed by the finite element analysis of a spinning disc. This result is in itself interesting since it shows that the important features regarding loss of uniqueness and localization in fiber reinforced composites are independent of whether or not a homogeneous shear free stress field is present.

The finite element results also show that loss of uniqueness and localization occur very close to load levels used in service; a finding that underlines the importance of giving due consideration to such failure modes, also at the manufacturing stage.

Acknowledgements-The authors gratefully acknowledge the financial support of the U.S. Air Force through contract AFOSR-90-0132 with the Department of Mechanical and Environmental Engineering, University of California at Santa Barbara.

\section{REFERENCES}

Abaqus (1989). Hibitt. H. D., Karlsson. B. I. and Sorenson. P., Inc., version 4.8.

Allix. O., Gilletta. D. and Ladevèze. P. (I985). Mechanical behavior of elementary constituents of laminates. 5th International Conference on Composites Materials, San Diego, CA, August 1985.

Benallal, A., Billardon. R, and Geymonat. G. (1991). Localization phenomena at the boundaries and interfaces of solids. 3rd Conference on Constitutive Laws for Engineering Materials: Theory and Applications, Tucson, AZ, January 1991 .

Billardon, R. and Doghri, I. (1989a). Prévision de l'amorçage d'une macro-fissure par la localisation de l'endommagement. C. R. Acad. Sci. Paris 308(II), 347-352.

Billardon. R. and Doghri, I. (1989b). Localization bifurcation analysis for damage softening elasto-plastic materials. In Strain Localization and Size Effect due to Cracking and Damage. (Edited by J. Mazars and Z. P. Bazant), pp. 295-307. Elsevier, Amsterdam.

Borré. G. and Maier. G. (1989). On linear versus nonlinear flaw rules in strain localization analysis. Meccanica 24, 36-4l.

Coleman. B. D. (1958). On the strength of classical fibers and fiber bundles. J. Mech. Phys. Solids 7, 60-70.

Davies, D. G. S. (1973). The statistical approach to engineering design in ceramics. P. Brit. Ceram. Soc. 22, 429452.

Doghri. I. (1989). Etude de la localisation de l'endommagement. Thèse de l'Université Paris 6. May 1989.

Hadamard. J. (1903). Leçon sur la propagation des ondes et les équations de l'hydrodynamique. Paris.

Hayhurst. D. R.. Leckie. F. A. and Evans, A. G. (1988). Component design-based model for deformation and rupture of tough fiber reinforced ceramic-matrix composites. Internal Report, U.C.S.B., October 1988.

Hill, R. (1962). Acceleration waves in solids. J. Mech. Phys. Solids 10, 1-16.

Hult. J. and Travnicek, L. (1983). Carrying capacity of fiber bundles with varying strength and stiffness. J. Méc. Théor. Appliq. 2(2). 643-657.

Kadlecek. V. and Spetla, Z. (1967). Effect of size and shape of test specimens on the direct tensile strength of concrete. Bull. RILEM 36, 175-184.

Katamaya, Y. and Hattori, Y. (1982). Effects of specimen size on strength of sintered silicon nitride. C. J. Am. Ceram. Soc. C-164/C-165.

Krajcinovic. D. and Silva, M.A.G. (1982). Statistical aspects of the continuous damage theory. Int. J. Solids Structures 18(7), 551-562.

Lemaitre. J. and Chaboche. J.-L. (1990). Mechanics of Solid Materials. Cambridge University Press, Cambridge.

Mandel. J. (1962). Ondes plastiques dans un milieu indéfini à trois dimensions. J. Mécanique I(1), 3-30.

Ortiz, M.. Leroy. Y. and Needleman. A. (1987). A finite element method for localized failure analysis. Comput. Keth. Appl. Engng 61, 189-214.

Rabotnov. Y. N. (1963). On the equations ol state for creep. In Progress in Applied Mechanics, Prager Anniversary Vol. p. 307. McMillan. New York.

Rice. J. R. (1976). The localization of plastic deformations. In Theoretical and Applied Mechanics (Edited by W T. Koiter). pp. 207-220. North-Holland, Amsterdam.

Rice. J. R, and Rudnicki. J. W. (1980). A note on some features of the theoroy of localization of deformation. Int. J. Solids Structures 16, 597-605.

Rudnicki. J. W. and Rice, J. R. (1975). Conditions for localization of deformation in pressure-sensitive dilatant materials. J. Mech. Phys. Solids 23, 371-394.

Weibull, W. (1939a). A statistical theory of the strength of materials. Ing. Vetenskap Akad.; Handlingar Nr 151.

Weibull, W. (19396). The phenomenon of rupture in solids. Ing. Vetenskap Akad., Handlingar $\mathrm{Nr} 153$. 


\section{APPENDIX A}

$$
\begin{gathered}
\dot{\boldsymbol{\Psi}}_{i f}=\boldsymbol{H}_{l j k l} \dot{\boldsymbol{\epsilon}}_{k l,} \\
{[X]=X^{+}-X^{-},} \\
{[\dot{\mathbf{u}}]=0,} \\
{\left[\dot{\boldsymbol{\Psi}}_{l, \mathbf{n}_{f}}\right]=0 .}
\end{gathered}
$$

Maxwell's compatibility equation $\left[\dot{\epsilon}_{l}\right]=\frac{1}{2}\left[g_{i} \mathbf{n}_{\jmath}+\mathbf{n}_{i} \mathbf{g}_{j}\right]$,

$$
0=\left[\dot{\boldsymbol{\sigma}}_{i j} \mathbf{n}_{j}\right]=\left[\dot{\boldsymbol{\sigma}}_{i j}\right] \mathbf{n}_{j}=\left[\mathbb{H}_{i j k i} \dot{\epsilon}_{k j}\right] \mathbf{n}_{j} .
$$

If we assume there is a discontinuity across the surface characterized by $\mathrm{n}$, then $\mathrm{H}^{+}=\mathrm{H}^{-}$

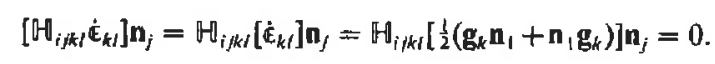

Since we assume that $H$ has the minor symmetries $\mathrm{HH}_{i k k l}=\mathrm{H}_{i, k l}=\mathrm{H}_{i j / k}$,

$$
\left[\mathbf{n}_{t} \mathbb{H}_{i j k} \mathbf{n}_{1}\right] \mathbf{g}_{k}=\mathbf{0} \text {. }
$$

This equality has to be satisfied for $\mathbf{g}$ different from zero. This imposes that for the matrix $\mathbf{n} \cdot \mathbb{H} \cdot \mathbf{n}$ to be singular

$$
\operatorname{Det}(n \cdot \mathbb{n} \cdot \boldsymbol{n})=0 \text {. }
$$

$$
\begin{aligned}
& \text { APPENDIX B } \\
& k=\frac{E_{x}}{E_{1}} . \\
& F_{1}=\frac{E_{2}}{k\left(1-v_{12}^{2}\left(1-D_{2}\right) k\right)}, \\
& F_{2}=\frac{E_{2} v_{12}\left(v_{12} \varepsilon_{11}+\varepsilon_{23}\right)}{\left(1-v_{12}^{2}\left(1-D_{2}\right) k^{2}\right.} . \\
& F_{4}=\frac{E_{2} v_{12}\left(1-D_{2}\right)}{1-v_{i 2}^{2}\left(1-D_{2}\right) k} . \\
& F_{5}=\frac{E_{2}\left(v_{12} \varepsilon_{11}+\varepsilon_{22}\right)}{\left(1-v_{12}^{2}\left(1-D_{2}\right) k\right)^{2}} \text {. } \\
& F_{6}=\frac{E_{2}\left(1-D_{2}\right)}{1-v_{12}^{2}\left(1-D_{2}\right) k} \text {. } \\
& F_{3}=\frac{m V}{V_{m} \varepsilon_{m}}\left(\frac{\varepsilon_{32}}{\varepsilon_{m}}\right)^{m-1} \exp \left[-\frac{V}{V_{m}}\left(\frac{\varepsilon_{22}}{\varepsilon_{m}}\right)^{m}\right] \text {. } \\
& F_{7}=\frac{\frac{m V}{V_{m} \sigma_{m}}\left[\frac{\sigma_{22}}{\left(1-D_{2}\right) \sigma_{m}}\right]^{m-1}}{1-m\left[\frac{\sigma_{22}}{\left(1-D_{2}\right) \sigma_{m}}\right]^{m}} .
\end{aligned}
$$

APPENDIX C

Material parameters for the ceramic-matrix fiber composite analysed in the finite element calculations are:

$$
\begin{gathered}
E_{1}=20 \mathrm{GPa}, \\
E_{2}=140 \mathrm{GPa}, \\
G_{12}=13 \mathrm{GPa}, \\
r_{13}=0.0214 . \\
m=4 . \\
\sigma_{m}=1453 \mathrm{GPa} . \\
r_{0}=0.002 \mathrm{~m} .
\end{gathered}
$$

